UDC $1: 316$

LBC 87.6

\title{
ARISTOTEL'S TEACHING ON VIRTUES AND ITS SOCIAL PROSPECTS
}

\author{
Roman Yu. Runaev \\ Volgograd Academy of the Ministry of the Interior of Russia, Volgograd, Russian Federation
}

\section{Olga N. Didenko}

Volgograd State University, Volgograd, Russian Federation

\begin{abstract}
The article is devoted to the issue of an understanding of a person's way of life through the prism of perception of Aristotle's ethical teachings as an important element of human culture, expressed in the virtuous attitude of people to the world. The presented article reveals the key aspects of virtue in the "Aristotelian" sense and the understanding of the correctness of human actions by the ancient philosopher. As the main value and moral guideline, the scale of virtuous knowledge developed by Aristotle is considered, where virtue itself is the "golden mean", and extremes (vices) are found on different sides of the latter. This work reflects the views of the ancient philosopher on human virtue. He considers the right actions of a person from the point of view of conscious moderation and reasonable prudence in their commission while rejecting the desire to help a person at any cost, as the basis of the measure virtue. Aristotle sees the achievement of "happiness" as the main goal of human behavior. But a feeling of satisfaction from the blissful state should not be expressed as a result of neglect of the moral principles of society but rather through personal growth, achieved through self-improvement, self-restraint, and detachment from attachment to the benefits of the outside world. According to Aristotle, sensory pleasures are achieved not by striving to achieve a comfortable existence in any way but by sensible and moderate motives of a person to feel genuine pleasure through the right actions. It is noted that the Aristotelian doctrine of virtue requires its theoretical understanding and analysis within the framework of the ethics of virtue, which claims to be the practical application of its results in modern society.
\end{abstract}

Key words: virtue, right action, ethical concept, ethics of virtue, moral philosophy, eudaimonism.

УДК $1: 316$

ББК 87.6

\section{УЧЕНИЕ АРИСТОТЕЛЯ О ДОБРОДЕТЕЛЯХ И ЕГО СОЦИАЛЬНЫЕ ПЕРСПЕКТИВЫ}

\author{
Роман Юрьевич Рунаев \\ Волгоградская академия МВД России, г. Волгоград, Российская Федерация
}

Ольга Николаевна Диденко

Волгоградский государственный университет, г. Волгоград, Российская Федерация

Аннотация. Статья посвящена вопросу осмысления человеком своего жизненного пути через призму
этического учения Аристотеля о добродетельном отношении людей к окружающему миру. В представлен-
ной статье раскрыты ключевые стороны добродетели в «аристотелевском» смысле и понимание античным
философом правильности человеческих поступков. В качестве основного ценностно-нравственного ориен-
тира рассмотрена разработанная Аристотелем шкала добродетельного познания, где «золотой серединой»
является сама добродетель, а на полюсах находятся крайности (пороки). Проанализированы воззрения ан-
тичного философа на человеческую добродетельность, своеобразие которой заключается в оценке правиль-
ных поступков человека с точки зрения осознанной умеренности и разумной рассудительности при их со- 
вершении. При этом желание помочь человеку любой ценой не рассматривается в качестве основы добродетельности. Основной целью человеческого поведения Аристотель видит достижение «счастья», но ощущение удовлетворения от своего блаженного состояния не может быть связано с пренебрежением моральными устоями общества, но должно быть реализовано через личностный рост, достижимый посредством самосовершенствования, самоограничения, отрешения от привязанностей к благам внешнего мира. Согласно Аристотелю получение чувственных наслаждений достигается не стремлением любым способом достичь комфортного существования, а в разумных и умеренных побуждениях человека ощутить подлинное удовольствие через совершаемые им правильные поступки. Показано, что аристотелевское учение о добродетели является этической концепцией, которая претендует на практическое применение и сохраняет актуальность в условиях современного общества.

Ключевые слова: добродетель, добродетельность, правильный поступок, этическая концепция, этика добродетели, моральная философия, эвдемонизм.

Традиция изучения добродетели, заложенная Аристотелем, приобретает сегодня особую мировоззренческую и методологическую значимость в связи с разработкой этики добродетели как самостоятельной этической концепции. «Особенность этики добродетели состоит в том, что ее авторы стремятся переосмыслить мораль, обращаясь к античному и средневековому наследию. Они противопоставляют этику добродетели теориям, использующим в качестве ключевых понятия морального долга, правильного, принципов и т. п. и анализирующим в первую очередь действия человека, его поведение» [Артемьева 2005, 163]. Актуальность теоретического осмысления аристотелевского учения о добродетели определяется и тем, что оно позволяет найти адекватные способы анализа и решения проблем современного общества. Так, А. Макинтайр указывает на то, что «отказ от рассмотрения социальных аспектов морали означал бы решительный отказ от моральной философии. Это также показывает, что, пока мы не примем во внимание социального воплощения моральной философии, мы непоймем полностью сути самой моральной философии» [Макинтайр 2000, 38].

Приступая к анализу учения о добродетели Аристотеля, отметим, что он видел цель существования человеческой личности в наполнении его определенным смыслом. И этот смысл он напрямую связывал с теми позитивными свойствами характера, которые человек проецирует на свою жизнь, «расточает» на окружающий мир, делает источником правильного поведения. Данные характерологические качества, как считал Аристотель, человек обязан не просто «посеять» в себе, но и каждодневно развивать и совершенство- вать своим трудом над собой и своим отношением к жизни и окружающим. Тем самым «человек разумный» убедительно доказывает, что живет не зря, а осмысленно. Совершенный или искусный человек всегда знает, что сказать; всегда может разрядить напряженную обстановку; умеет сообщать плохие новости; уверен в себе, но не высокомерен; храбр, но не безрассуден; щедр, но не расточителен. Это такой человеческий «типаж», с которым все хотят быть рядом, он поневоле притягивает к себе других людей, которые хотят быть на него похожими ввиду его очевидно позитивной сущности. Экзистенция такого человека заключена в свойственных ему идеалах, главное назначение которых - осмысленно и деятельно расточать «разумное, светлое, вечное». Основной критерий идентификации такого человеческого «типа» - степень овладения искусством «быть человеком». Этот идеал может показаться недостижимым, однако Аристотель верил, что такие люди существуют. Следовательно, каждый человек может и должен стремиться достичь этого идеала, стать «добродетельным».

На учении о добродетелях основан значительный пласт этических рассуждений и выводов. При этом оно не раскрывает перед нами смысл того, что именно нужно делать для достижения позитивной сути бытия. Здесь нет какого-либо категорического императива либо принципа пользования собственным сознанием во имя достижения неких эфемерных идеалов. Вместо этого данное учение всецело фокусируется на человеческом характере. Оно не говорит нам: «следуй этим правилам и будешь хорошим человеком». Аристотель и его единомышленники убеждают нас: если мы 
просто сосредоточимся на том, чтобы быть хорошими людьми, правильные поступки последуют за этим сами собой. Станешь хорошим человеком - и начнешь поступать правильно, ведь для этого не нужно никаких сводов правил. Но зачем нужно быть «добродетельным» человеком?

В древнегреческой философии стремление к достижению счастья становится основным критерием нравственности в деятельности и творчестве человека, делающего правильный выбор в своих действиях и поступках. Эвдемонизм в классическом понимании - такая жизненная установка, при которой наивысшим и единственным благом человека является «счастье», к достижению которого человек должен стремиться всеми приемлемыми для общества способами. Счастье это особый тип человеческой морали, который согласно Аристотелю «...мы всегда избираем ради него самого и никогда ради чегото другого...» [Аристотель 1983, 62]. Приверженцы данного этического направления рассматривали достижение «блаженства» как основной мотив своих жизненных устремлений, ради которого надо совершенствовать свои индивидуальные навыки и возможности. Абсолютно счастливым и в то же время добродетельным человеком эвдемонисты считали того, кто, развивая собственные телесные и духовные способности, доставляет удовольствие не только себе, но и другим. Только в этом случае имеют смысл все добродетели человека, только так можно рассчитывать на уважение современников и память потомков.

Аристотелевское учение о добродетелях отражает древнее предположение о том, что человек обладает уже упомянутой выше позитивной экзистенцией и если мы остаемся верными собственной этической сущности, то процветаем. При этом, как считал Аристотель, в любое живое существо, выполняющее определенную функцию, априори закладывается «нечто природное и прекрасное». «Ибо, - писал античный философ, - не случайность, но целесообразность присутствует во всех произведениях природы, и ... ради какой цели они существуют или возникли - относится к области прекрасного» [Аристотель 1937, 50]. Человеку как живому существу присущи все функции, относящиеся к животным. Он дол- жен расти, быть здоровым и плодовитым, но при этом он - «животное разумное» и «животное социальное», так что к его функциям добавляются «размышление» и «нахождение общего языка» с себе подобными. Аристотель утверждал, что сама природа встроила в нас, стремящихся достичь абсолютного «счастья», функцию стяжания добродетели.

Но что именно означает «быть добродетельным»? Аристотель разъясняет, что «добродетельность» подразумевает «правильный поступок», совершенный в нужный час, должным образом, без «ударения в крайности». Аристотель утверждает, что в разъяснении этого понятия нет необходимости, потому, что если ты «добродетельный», то ты и так знаешь, что делать. Ты знаешь, как себя вести и ладить с окружающими. Ты обладаешь высокой степенью рассудительности, можешь верно оценить обстановку и понять, что правильно и когда.

Аристотель понимал этическую сторону «добродетелей» как набор укоренившихся черт характера, которые, будучи однажды развиты, приведут к должному поведению. По мнению Аристотеля, нравственные добродетели «существуют в нас не от природы и не вопреки природе, но приобрести их для нас естественно, а благодаря приучению мы в них совершенствуемся» [Аристотель 1983, 78]. Но такие добродетели, как мужество, благоразумие, щедрость, великолепие, величавость, не могут быть «абсолютными» в своем проявлении. «Добродетель... есть некое обладание серединой, во всяком случае, она существует постольку, поскольку ее достигает», это «способность поступать наилучшим образом (во всем. - P. P., О. Д.), что касается удовольствий и страданий, а порочность - это ее противоположность» [Аристотель 1983, $82,86]$. Такие «крайности» Аристотель также именует «пороками», а умение воздерживаться от них, избегать любых недостатков в своем поведении он и определяет как добродетельное свойство человеческого характера.

Рассмотрим такую добродетель, как «мужество». Что должен сделать мужественный человек в ситуации, когда на его глазах происходит преступление? Несомненно, нужно ему воспрепятствовать, в том числе с риском для себя, поскольку мужество означает 
«подвергание себя опасности ради благого дела». Но согласно учению Аристотеля это не совсем так. Добродетельный человек в «аристотелевском» смысле сначала оценит ситуацию и, лишь осознав свое полное «антропометрическое» и прочее превосходство (в физической силе, росте, весе, познаниях в боевых единоборствах) над преступником, вступит с ним в относительно безопасное для себя противостояние. Именно это и будет в его понимании «мужественным поступком». Если же вы заведомо слабее преступника и, оценив ситуацию, осознаете, что может пострадать не только жертва, но и вы сами, то согласно Аристотелю храбростью будет не «вмешаться», а «позвать на помощь». Именно так добродетельный человек деятельно проявит свое желание противостоять творимому злу. В связи с этим мужество - это и будет «золотой серединой» между «крайностями»: трусостью и безрассудством. Аристотель, таким образом, говорит нам, что даже с «хорошим» необходимо знать меру. Быть мужественным - не значит опрометчиво бросаться навстречу опасности. «Мужественный - непоколебим, насколько это возможно человеку; поэтому он страшится опасностей, но так страшится, как следует, как приказывает разум и ради прекрасной цели; в этом и заключается цель добродетели», в то время как человек, переступающий границы в бесстрашии, походил бы на «беснующегося и бесчувственного...» [Этика Аристотеля 1908, 51-52].

По мнению философа, все «добродетели» работают подобным образом. Правильный поступок является искомой «серединой» между отвергаемыми Аристотелем «крайностями». В этой теории мы найдем место и другой значимой человеческой добродетели «правдивости». По рассматриваемой шкале крайностями являются «радикальная правдивость» и «неспособность сказать то, что сказать нужно». Добродетель «правдивости» предполагает не только знание того, что стороннему человеку просто необходимо сообщить, но и того, о чем следует промолчать. А еще это означает умение аккуратно говорить неприятную правду, корректно сообщать плохую новость или критиковать так, чтобы не обидеть оппонента.
Аналогичным образом работает еще одна добродетель - «щедрость». Она подразумевает избегание не только очевидного людского порока - «скупости», но также и «безотказности» как полюса по «шкале крайностей» у данной добродетели. Верная «мера» щедрости означает давать, когда есть что давать, и лишь тем, кто в этом нуждается. Это означает не только склонность давать безвозмездно, но еще и понимание, когда давать не следует. Предложенная Аристотелем формула «жить согласно мере» связана с определенными трудностями в ее реализации, так как «золотая середина» в выборе человеком правильного поступка полностью зависит от каждой конкретной ситуации. И каждый раз мы снова и снова должны отвечать на вопрос о добродетельности наших действий.

Аристотель полагал, что научить правильной оценке таких ситуаций людям помогают книги, но вот «быть хорошим человеком» они не научат. Он говорил, что добродетельные качества не присутствуют изначально в человеке, а только воспитываются. Это навыки, которые приходят лишь с «опытом». Любой человек способен посвятить их усвоению свою жизнь, если вступит на путь самопознания и самосовершенствования, начнет всемерно развивать свое позитивное «начало», поскольку именно в этом его истинное предназначение. И нет согласно Аристотелю абсолютно потерянной для общества человеческой «сущности», но есть такие люди, которые сознательно отдаляют себя от «добродетелей» и подавляют в себе стремление следовать им.

Вполне очевидно, что общества во все времена были далеко не такими этически «добродетельными», какими их хотел бы видеть основоположник рассматриваемого учения. В Спарте, как известно, у слабых и больных детей не было шанса выжить. Платон считал убийство «дефектных детей» лучшим средством регуляции численности населения. Не лучше подчас поступали у древних народов и со стариками. Можно привести множество примеров бесчеловечных деяний в привязке к человеческой деградации как таковой, когда люди перестают распознавать границы «хорошего» и «плохого». Будучи отвлеченными от добродетельного пути, люди оказыва- 


\section{НАУЧНЫЕ СООБЩЕНИЯ}

ются в пагубной власти таких аффективных проявлений, как суеверия, страсть, гнев, страх, нарциссизм и т. д. [Асмус 1998, 273].

В связи с этим Аристотель, стремясь преодолеть описанные «разрушительные» для человеческой морали тенденции, писал: «Ведь кто живет по страсти, пожалуй, и слушать не станет рассуждения, которые отвращают... (его от страсти. - Р. Р., О. Д.)» [Аристотель 1983, 288]. Достижение счастья, по его мнению, возможно только в результате преодоления стремления к чувственным наслаждениям путем самосовершенствования, самоограничения, отрешения от привязанностей к благам внешнего мира. И эта «разумность» рассматривалась им как тождественная подлинной добродетели. Трудам Аристотеля «вторили» и другие древние философы. Киники формулируют в качестве жизненного принципа борьбу со страстями, порабощающими человека. Эпикур учит о подчинении чувственных удовольствий разуму; Антисфен отождествляет стремление к удовольствиям с сумасшествием; Аристокл считает, что лучше вытерпеть страдания, чтобы насладиться большими удовольствиями [Дынник (ред.) 1955, 37, $153,233]$.

Таким образом, борьбу с человеческими страстями в стремлении избежать нравственной деградации можно воспринять как основной смысл человеку быть преисполненным добродетелями. Учение Аристотеля скорее связано с рационализмом человеческого мышления как способом разумного познания мира, нежели с прагматизмом, который стремится объяснить человеку, что в основе его действий должен лежать принцип «полезности». Между тем представляется, что человек и сам в состоянии осознать добродетельную значимость своих поступков. Дело в том, что добродетельные качества должны проявляться в человеке не из расчетливого стремления «быть хорошим», а потому, что, распознав «пограничную» суть хороших и плохих поступков, истинно добродетельный человек осознанно заключает: «Я на стороне добра!». С этого момента данное смыслоутверждение становится его «жизненным кредо».

В связи с этим «добродетель» - это знания, которые Аристотель еще называл «жи- тейской мудростью». Характер человека закаляется «нравами-привычками»: что справедливыми люди становятся, поступая справедливо, благоразумными - поступая благоразумно, храбрыми - действуя храбро. Чтобы поступать правильно, человеку необходимо обладать практической мудростью либо следовать примеру или наставлениям добродетельного человека. Добродетелям учатся, наблюдая за поступками добродетельного человека и повторяя их. Научиться поступать добродетельно можно, если найти тех, кто уже умеет так поступать, после чего следует во всем брать с них пример. Эти люди, которые уже владеют добродетелями, являются «образцами подражания» и согласно учению Аристотеля в нас уже встроена и способность распознавать таких людей, и даже само желание им подражать [Аристотель 1983, 24-25].

Данные утверждения очень созвучны с христианской моралью. Так, самыми значимыми примерами добродетельного пути для искренне верующих людей являются жития святых - людей из плоти и крови, которые в своей духовной практике достигли таких высот, что являли подлинный пример для подражания в своем нестяжательстве, послушничестве, добродетели. При этом эти уникальные люди, по мере своих сил расточая земной «свет» своими правильными поступками, не считали это прижизненным подвигом, а свой добродетельный путь старались сделать тихим и незаметным.

Согласно Аристотелю, «...если добродетели не суть ни аффекты, ни способности, то остается лишь признать их приобретенными качествами души» [Этика Аристотеля 1908, 29]; «...всякая добродетель доводить до совершенства то, добродетелью чего она является и деятельность этой душевной способности ведется ею в совершенстве» [Этика Аристотеля 1908, 29]. Сложность этого пути связана с тем, что сначала человек может чувствовать неестественность происходящего, потому что он подражает тому, кто лучше его, но со временем эти поступки прочно укореняются в характере и в дальнейшем они станут неизменной чертой, которая будет проявляться каждый раз, когда она необходима. Когда добродетель перестанет требовать уси- 
лий, тогда человек поймет, что овладел ею сполна.

Так что же в конечном итоге должно нас мотивировать, зачем мы должны подражать тем, кто говорит и делает правильные вещи или всегда находит смелость в нужные моменты? Аристотель указывает на то, что нам следует стать добродетельными, потому что только тогда мы сможем достичь вершины человечности, прожить счастливую жизнь. Эта жизнь полна стремлений, в ней приходится выжимать из себя максимум и добиваться успеха, такая жизнь преисполнена счастьем от достижения чего-то сложного. Люди, выбравшие эвдемоническую жизнь, никогда не перестают самосовершенствоваться, никогда не живут просто «по инерции». Представители такого типа людей постоянно ставят перед собой новые цели и стремятся их достичь с добропорядочным усердием [Аристотель 1983, 33]. Их наградой является удовлетворение достижения предела человеческих «высот», сознания, что он сделал все, что мог, чтобы стать еще лучше. Быть лучше самого себя, оттачивать свои сильные стороны и работать над своими недостатками является для Аристотеля высочайшей моральной вершиной. Древнегреческий философ искренне считал, что человек, который живет сообразно разработанному им этическому учению, проживет хорошую жизнь, наполненную значимыми человеческими смыслами. По мнению А. Макинтайра, «аристотелевская традиция может быть вновь воссоздана таким образом, который придает разумность и рациональность нашим моральным и социальным позициям и обстоятельствам» [Макинтайр 2000, 352].

\section{СПИСОК ЛИТЕРАТУРЫ}

Аристотель 1937 - Аристотель. О частях животных: пер. с греч. М.: Биомедгиз, 1937.

Аристотель 1983 - Аристотель. Никомахова этика // Сочинения. В 4 т. Т. 4. М.: Мысль, 1983. C. 53-293.

Артемьева 2005 - Артемьева О.В. У истоков современной этики добродетели // Этическая мысль. 2005. Вып. 6. С. 163-181.

Асмус 1998 - Асмус В.Ф. Античная философия. М.: Высш. шк., 1998.

Дынник (ред.) 1955 - Дьнник М.А. (ред.). Материалисты Древней Греции. М.: Гос. изд-во полит. лит., 1955.

Макинтайр 2000 - Макинтайр А. После добродетели: Исследования теории морали. М.: Академ. Проект; Екатеринбург: Деловая кн., 2000.

Этика Аристотеля 1908 - Этика Аристотеля: пер. с греч.: с прил. «Очерка истории греческой этики до Аристотеля» Э.Радлова. СПб.: Филос. о-во при Имп. Санкт-Петербург. Ун-те, 1908.

\section{REFERENCES}

Aristotle, 1937. About Animal Parts. Moscow, Biomegiz. Aristotle, 1983. Nicomachean Ethics. Compositions. In 4 vol. Vol. 4. Moscow, Mysl.

Artemyeva O.V., 2005. At the Origins of Modern Ethics of Virtue. Ethical Thought, vol. 6, pp. 163-181.

Asmus V.F., 1998. Ancient Philosophy. Moscow, Vyssh. shk., 1998.

Dynnik M.A. (ed.), 1955. Materialists Of Ancient Greece. Moscow, Gos. izd-vo polit. lit.

MacIntyre A., 2000. After Virtue: Studies of the Theory of Morality. Moscow, Akadem. Proekt; Yekaterinburg, Delovaja kn.

The Ethics Of Aristotle. With Application "Essay on the history of Greek ethics before Aristotle" by E. Radlov, 1908. Saint Petersburg, Filos. o-vo pri Imp. Sankt-Peterburg. Un-te. 


\section{Information About the Authors}

Roman Yu. Runaev, Candidate of Sciences (Philosophy), Senior Lecturer, Department of the Philosophy, Volgograd Academy of the Ministry of the Interior of Russia, Historic St., 130, 400089 Volgograd, Russian Federation, donnash@mail.ru, https://orcid.org/0000-0003-3313-9626

Olga N. Didenko, Candidate of Sciences (Philosophy), Associate Professor, Department of Philosophy, Volgograd State University, Universitetsky Prosp., 100, 400062 Volgograd, Russian Federation, didenko@volsu.ru, https://orcid.org/0000-0002-1524-8813

\section{Информация об авторах}

Роман Юрьевич Рунаев, кандидат философских наук, старший преподаватель кафедры философии, Волгоградская академия МВД России, ул. Историческая, 130, 400089 г. Волгоград, Российская Федерация, donnash@mail.ru, https://orcid.org/0000-0003-3313-9626

Ольга Николаевна Диденко, кандидат философских наук, доцент кафедры философии, Волгоградский государственный университет, просп. Университетский, 100, 400062 г. Волгоград, Российская Федерация, didenko@volsu.ru, https://orcid.org/0000-0002-1524-8813 